\title{
Fruit Quality and Chemical Contents of Hybrid Boysenberry (Rubus ursinus) Lines Developed by Hybridization and Gamma Irradiation
}

\author{
Jaihyunk Ryu ${ }^{1}$, Soon-Jae Kwon ${ }^{1}$, Yeong Deuk Jo ${ }^{1}$, Hong-Il Choi ${ }^{1}$, Kyung-Yun Kang ${ }^{2}$, Bo mi Nam ${ }^{1}$, Dong-Gun Kim ${ }^{1}$, \\ Chang-Hyun Jin', Jin-Baek Kim, Ee-Yup Kim³ ${ }^{3}$, Seung Cheol $\mathrm{Oh}^{3}$, Bo-Keun $\mathrm{Ha}^{4}$, Si-Yong Kang ${ }^{1 *}$ \\ ${ }^{1}$ Advanced Radiation Technology Institute, Korea Atomic Energy Research Institute, Jeongup 56212, Korea \\ ${ }^{2}$ Suncheon Research Center for Natural Medicines, Suncheon 57922, Korea \\ ${ }^{3}$ Bioplus Co., Wanju 55310, Korea \\ ${ }^{4}$ Division of Plant Biotechnology, College of Agriculture and Life Science, Chonnam National University, Gwangju 61186, Korea
}

\begin{abstract}
The Rubus fruit is an economically important berry crop that contains various functional compounds. The objective of this study was to analyze fruit qualities (i.e., $\mathrm{pH}$, soluble solids content, titratable acidity, and mineral content) as well as fatty acid and phenolic compounds (i.e., ellagic acid and anthocyanins) among hybrid boysenberry lines developed by hybridization and gamma irradiation. There were no significant differences in the hybrid boysenberry fruit $\mathrm{pH}$ and titratable acidity (\%) among the tested genotypes. However, the soluble solids content was higher in the BSA119 and BSA144 mutants than in the original genotype (BS_Hybrid). Meanwhile, linoleic acid was the most abundant fatty acid in the analyzed hybrid boysenberry fruits. The fatty acid composition did not differ significantly among the genotypes. The ellagic acid content of all genotypes ranged from $8.72 \mathrm{mg} / 100 \mathrm{~g}$ to $46.10 \mathrm{mg} / 100 \mathrm{~g}$, with the highest concentration observed for the BSB127 genotype. Additionally, cyanidin-3-O-sophoroside (M- $\left.\mathrm{H}^{+}, 611 \mathrm{~m} / \mathrm{z}\right)$ and cyanidin-3-O-glucoside $\left(\mathrm{M}-\mathrm{H}^{+}, 449 \mathrm{~m} / \mathrm{z}\right)$ were the two major anthocyanins detected in the boysenberry and mutant genotypes, while cyanidin-3-O-glucoside was the predominant blackberry anthocyanin. The total anthocyanin concentrations of four mutant genotypes (i.e., BSA036, BSA078, BSA101, and BSB127) were significantly higher than that of the original genotype (382.0 mg/100 $\mathrm{g})$. The highest total anthocyanin concentration was observed for the BSA078 genotype ( $467.9 \mathrm{mg} / 100 \mathrm{~g})$. These results may be useful for identifying the optimal genotypes for breeding new cultivars with enhanced qualities and potential health benefits.
\end{abstract}

Keywords Edible oils, GC-MS, LC-MS, Mutation breeding, Phenolic compounds, Phytochemicals, Thornless mutant

\section{INTRODUCTION}

Boysenberry (Rubus ursinus Chamisso \& Schlenhtendal) is a hybrid Rubus berry derived from a cross between loganberry (Rubus loganobaccus Bailey) and trailing blackberry (Rubus fruticosus L.) (Zafra-Stone et al. 2007). Rubus fruits are recognized for the health benefits of their natural phytochemicals, such as phenolics, vitamin $\mathrm{C}$, minerals, and fatty acids (Kaume et al. 2012; Lee et al. 2012; Lee et al. 2014). These fruits are rich in phenolics, and the contribution of these compounds to antioxidant activities will be of interest to breeders whose goals include developing new varieties that produce higher quality and healthier fruits than what is currently available (Wada and $\mathrm{Ou}$ 2002; Parry et al. 2005; Guedes et al. 2013). Anthocyanins and ellagic acid are abundant phenolic compounds in Rubus fruits (Wada and Ou 2002; Cooney et al. 2004; Ryu et al. 2016). The potential health benefits of anthocyanins have led to a renewed interest in the consumption of foods rich in anthocyanins (e.g., berry fruits) and the bio-

Received June 19, 2017; Revised August 17, 2017; Accepted August 18, 2017; Published September 1, 2017

*Corresponding author Si-Yong Kang, sykang@kaeri.re.kr, Tel: +82-63-570-3310, Fax: +82-63-570-3319 
absorption of these phenolic compounds. Previous studies revealed that the possible positive health effects resulting from the intake of Rubus fruit anthocyanins include decreased oxidative stress, lowered serum cholesterol levels, and protection from liver ischemia-reperfusion injury (Cooney et al. 2004; Ghosh et al. 2006; Cho et al. 2015). Among the Rubus species, boysenberry has the most ellagic acid, which is a potential anticarcinogenic compound (Wada and Ou 2002). Additionally, specialty high-value Rubus fruits are gaining attention owing to their health benefits, which are linked to their abundance of polyunsaturated fatty acids (Parry et al. 2005; Van Hoed et al. 2009; Ferreira de Araujo et al. 2011).

Mutation breeding involves the use of a mutagen to create plants exhibiting a few new mutant characteristics that do not disturb other varietal traits. The fruit industry relies on a limited number of clonally propagated cultivars established based on specific fruit quality parameters and consumer familiarity with the product, and is very resistant to changes (Predieri et al. 2001; Kim et al. 2015; Jo et al. 2016; FAO/IAEA Mutant Variety Database [https://mvd.iaea.org/]). This limits the application of cross-breeding in fruit-bearing plant species, as fruit cultivars are generally highly heterozygous, and progenies resulting from cross-breeding express many traits that are different from those of the parents (Predieri et al. 2001; Jo et al. 2016; FAO/IAEA Mutant Variety Database). In Rubus species, mutagenesis has been used to manipulate various traits, including the presence of spines, fruit size and color, disease resistance, timing of maturity, yield, and cold-induced resistance to pathogens (Donini 1982; Ryu et al. 2016; FAO/IAEA Mutant Variety Database). Improved thornless cultivars have been produced by breeders to meet the demands of growers who wish to maintain an economic advantage in the marketplace. Additionally, evaluating boysenberry fruit resources regarding phytochemical contents is important and may be considerably beneficial for the food and pharmaceutical industries (Predieri et al. 2001; Clark et al. 2007; Ryu et al. 2016).

The objective of this study was to investigate the nutritional characteristics [i.e., mineral content, soluble solids content (SSC), and soluble sugar content] and functional compounds (i.e., anthocyanins, ellagic acid, and fatty acid) of Rubus genotypes.

\section{MATERIALS AND METHODS}

\section{Plant materials and harvest}

Eleven genotypes were analyzed in this study (Table 1). Among these genotypes, the BS_PI cultivars was introduced from Japan and produced spines, while the others were stabilized lines from advanced generations and were thornless (Fig. 1). The BS_Hybrid line was obtained from crosses between the thornless blackberry (Rubus fruticosus L. cv. V3) and boysenberry (Shin et al. 2008). V3 line was developed from spiny blackberry explants exposed to somaclonal variation. Six mutant genotypes (BSA036 to BSA144) were developed from hybrid boysenberry explants exposed to $20 \mathrm{~Gy}$ gamma radiation.

Table 1. Origin of hybrid boysenberry genotypes used in this study.

\begin{tabular}{|c|c|c|c|c|}
\hline No. & Line & Origin & Treatment & Stem spiny \\
\hline 1 & BS_PI & Boysenberry from Japan & & Spiny \\
\hline 2 & Blackberry (V3) & Hybrid Blackberry & Somaclonal variation & Thornless \\
\hline 3 & BS_Hybrid & Cross breeding & Blackberry(V3)'Boysenberry & Thornless \\
\hline 4 & BSA-036 & BS_Hybrid & Gamma-ray 20 Gy & Thornless \\
\hline 5 & BSA-065 & BS_Hybrid & Gamma-ray 20 Gy & Thornless \\
\hline 6 & BSA-078 & BS_Hybrid & Gamma-ray 20 Gy & Thornless \\
\hline 7 & BSA-101 & BS_Hybrid & Gamma-ray 20 Gy & Thornless \\
\hline 8 & BSA-119 & BS_Hybrid & Gamma-ray 20 Gy & Thornless \\
\hline 9 & BSA-144 & BS_Hybrid & Gamma-ray 20 Gy & Thornless \\
\hline 10 & BSB-032 & BS_Hybrid & Gamma-ray 40 Gy & Thornless \\
\hline 11 & BSB-127 & BS_Hybrid & Gamma-ray $40 \mathrm{~Gy}$ & Thornless \\
\hline
\end{tabular}




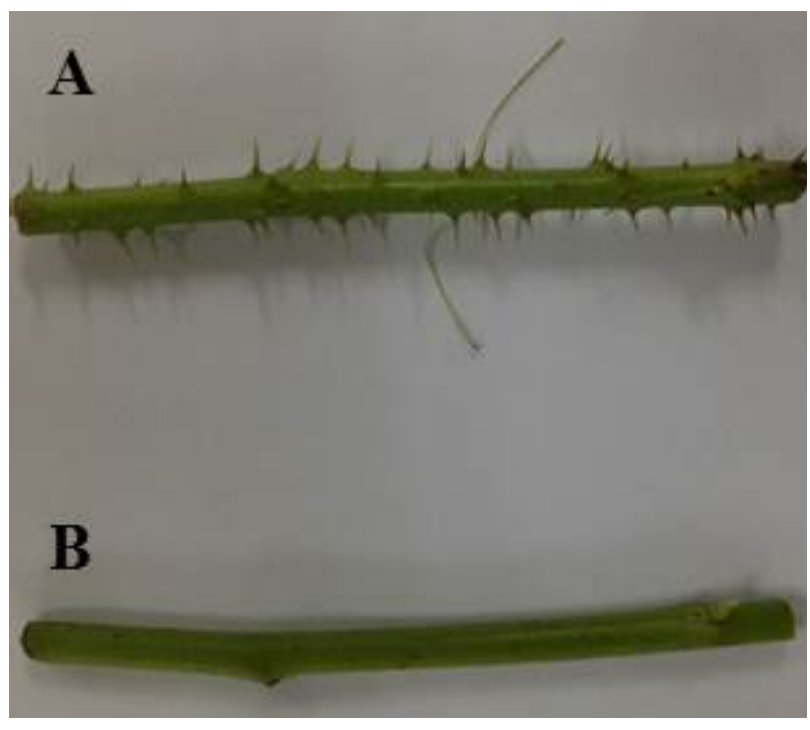

Fig. 1. Stem profile of boysenberry genotype used in this study. (A) Spiny, (B) thornless.

Another two mutant genotypes (BSB032 and BSB127) were produced from hybrid boysenberry explants treated with 40 Gy gamma radiation. The eight mutant lines exhibited improved agronomic characteristics, including higher fruit yields and sugar contents than the original parent. Fully ripened fruits were collected from a $3 \times 3 \mathrm{~m}^{2}$ quadrant. Three replicates were used for each sample.

\section{Estimation of pH, soluble solids content, and titratable acidity}

The $\mathrm{pH}$ was measured using a Docu-pH meter (Sartorius Inc., Göttingen, Germany). The SSC was determined using the PR-101 hand-held refractometer (Atago USA Inc., Bellevue, WA, U.S.A.). The titratable acidity (\%) was calculated according to the AOAC (1995) method.

\section{Mineral content}

We determined the mineral contents using the AOAC (1995) methods. Samples (1.0 g) were weighed and subjected to dry ashing in a clean porcelain crucible at $550^{\circ} \mathrm{C}$ in a muffle furnace. The resultant ash was dissolved in $5.0 \mathrm{~mL}$ nitric acid: hydrogen chloride: purified water (1:2:3) and gently heated on a heating mantle until the brown fumes disappeared. Then, $5.0 \mathrm{~mL}$ distilled water was added to each sample, which was then heated until a colorless solution was obtained. The mineral solution was filtered into a $100 \mathrm{~mL}$ volumetric flask. The elemental composition of the solution was analyzed in triplicate using a Model 403 atomic absorption spectrophotometer (Perkin Elmer, Waltham, MA, U.S.A.).

\section{Fatty acid composition}

Fatty acid composition was analyzed by gas chromatography-mass spectrometry (GC-MS). According to the Soxhlet extraction procedure, $5 \mathrm{~g}$ crushed dried fruit ( 80 mashed) was packed into a thimble and the oils were extracted with diethyl ether for $6 \mathrm{~h}$. The fruit lipid extracts were mixed with a $20 \%$ boron trifluoride-methanol reagent, and the fatty acids were converted into methyl ester derivatives. The methyl esters of the fatty acids were dissolved in chloroform and analyzed by GC-MS (Plus-2010; Shimadzu, Kyoto, Japan). The fruit fatty acid composition was analyzed using a GC-MS instrument equipped with an HP-88 capillary column $(60 \mathrm{~m} \times 0.25$ $\mathrm{mm}$; J \& W Scientific, CA, U.S.A.) under the following conditions: ionization voltage, $70 \mathrm{eV}$; mass scan range, $35-450$ mass units; injector temperature, $230^{\circ} \mathrm{C}$; detector temperature, $230^{\circ} \mathrm{C}$; injection volume, $1 \mu \mathrm{L}$; split ratio, 1:20; carrier gas, helium; and flow rate, $1.7 \mathrm{~mL} /$ minute. The column temperature program specified an isothermal temperature of $40^{\circ} \mathrm{C}$ for 5 minutes followed by an increase to $180^{\circ} \mathrm{C}$ at a rate of $5^{\circ} \mathrm{C} /$ minute and a subsequent increase to $230^{\circ} \mathrm{C}$ at a rate of $1{ }^{\circ} \mathrm{C} /$ minute. We identified the substances present in extracts by comparing their mass spectra against a database of GC-MS spectra (Nist. 62 Library) and based on their retention indices.

\section{Ellagic acid analysis}

The lyophilized, powdered fruits were diluted with purified water and methanol (37.5:63.5). We then added 10 $\mathrm{mL} 1.2 \mathrm{~mol}$ hydrogen chloride to the diluted mixture, which was refluxed for 16 hours at $80 \pm 5^{\circ} \mathrm{C}$. The extract was cooled and filtered through a $0.45 \mu \mathrm{m}$ membrane. The following gradients were used: 0-3 minutes, $10-20 \% \mathrm{~B}$; 3-6 minutes, $20-30 \% \mathrm{~B}$; 6-9 minutes, $30-50 \% \mathrm{~B}$; 9-15 minutes, $50-60 \% \mathrm{~B} ; 15-18$ minutes, $60-70 \% \mathrm{~B} ; 18-21$ minutes, $70-50 \%$ B; $21-24$ minutes, $50-30 \%$ B; and 24-27 minutes, $30-0 \%$ B. Ellagic acid was detected at $254 \mathrm{~nm}$ and 
identified using commercial standards (Sigma, St. Louis, MO, USA).

\section{Anthocyanin analysis}

Anthocyanins were extracted from samples as described by Ryu et al. (2016). Briefly, $0.5 \mathrm{~g}$ freeze-dried fruits were treated with $5 \mathrm{~mL}$ methanol:water:hydrochloric acid (70:29:1, v/v) at $4^{\circ} \mathrm{C}$ in darkness for 24 hours, with periodic vortexing. The material was filtered through a $0.45 \mu \mathrm{m}$ membrane filter. Three extract replicates were analyzed for each sample. The extracted anthocyanins were analyzed using a 1260 series high-performance liquid chromatography system, a 380 evaporative light scattering detector, and a 6130 quadrupole mass spectrometry system (Agilent Technologies, USA) equipped with a Poroshell 120 SB-C18 column $(150 \mathrm{~mm} \times 4.6 \mathrm{~mm}$ internal diameter, 2.7 $\mu \mathrm{m}$ particle size; Agilent Technologies, CA, U.S.A.) with a compatible $\mathrm{C} 18$ guard column $(4 \mathrm{~mm} \times 3 \mathrm{~mm}$ internal diameter, $3 \mu \mathrm{m}$ particle size; Phenomenex, CA, USA). The mobile phase was composed of water (A, $0.05 \%$ formic acid) in acetonitrile (B, $0.05 \%$ formic acid). The following gradients were used: 0-3 minutes, 95\% A and 5\% B; 3-28 minutes, $100 \% \mathrm{~B}$; and $28-35$ minutes, $100 \% \mathrm{~B}$. The flow rate of the mobile phase was adjusted to $0.5 \mathrm{~mL} /$ minute, and the column temperature was set to $24^{\circ} \mathrm{C}$. The injection volume was $10 \mu \mathrm{L}$. The optimum parameters were as follows: drying gas pressure, $12.0 \mathrm{~L} /$ minute; positive and negative capillary voltage, 3000 Volt; drying gas temperature, $350^{\circ} \mathrm{C}$; and nebulizer gas pressure, $35 \mathrm{psig}$
$\left(\mathrm{Lb} / \mathrm{in}^{2}\right)$. The MSD signal settings in the positive/negative mode were as follows: mass range $(\mathrm{m} / \mathrm{z}), 100-1000$; fragmentor, 70; and scan mode. The evaporative light scattering detector settings were as follows: gas flow rate, 1.60 SLM; LED intensity, 100\%; evaporative temperature, $30^{\circ} \mathrm{C}$; nebulizer temperature, $30^{\circ} \mathrm{C}$.

\section{Data analysis}

Data were subjected to analysis of variance using the multiple comparisons method of SPSS version 12 (SPSS Inc., Chicago, IL, USA). Correlation analyses were based on Pearson's correlation coefficient. A $P$-value $<0.05$ indicated statistical significance. If a treatment effect was determined to be significant, the means were differentiated using Duncan's multiple range tests.

\section{RESULTS}

\section{Estimation of $\mathrm{pH}$, soluble solids content, and titratable acidity}

The $\mathrm{pH}, \mathrm{SSC}$, and titratable acidity of the analyzed hybrid boysenberry fruits are listed in Table 2 . There were no significant differences in the $\mathrm{pH}$ and titratable acidity (\%) of Rubus fruits among genotypes. In contrast, the SSC value of the BS_Hybrid genotype was lower than that of the mother cultivars (i.e., boysenberry and blackberry). The SSC was higher in the BSA119 and BSA144 genotypes than in the original genotype (BS_Hybrid). The BSA101

Table 2. The hydrogen exponent, sugars content and titratable acidity of fruit for hybrid boysenberry genotypes.

\begin{tabular}{lccc}
\hline \hline Line & Hydrogen exponent & SSC $\left({ }^{\circ}\right.$ Brix $)$ & Titratable acidity $(\%)$ \\
\hline BS_PI & $3.7 \pm 0.1 \mathrm{a}^{\mathrm{z})}$ & $7.6 \pm 0.1 \mathrm{~b}^{\mathrm{z})}$ & $\left.1.8 \pm 0.2 \mathrm{a}^{\mathrm{z}}\right)$ \\
Blackberry (V3) & $3.6 \pm 0.0 \mathrm{a}$ & $7.4 \pm 0.2 \mathrm{bc}$ & $1.7 \pm 0.0 \mathrm{a}$ \\
BS_Hybrid & $3.8 \pm 0.2 \mathrm{a}$ & $6.0 \pm 0.3 \mathrm{~d}$ & $1.5 \pm 0.3 \mathrm{a}$ \\
BSA-036 & $3.6 \pm 0.1 \mathrm{a}$ & $6.1 \pm 0.2 \mathrm{~d}$ & $1.5 \pm 0.3 \mathrm{a}$ \\
BSA-065 & $3.8 \pm 0.0 \mathrm{a}$ & $6.3 \pm 0.2 \mathrm{~d}$ & $1.6 \pm 0.3 \mathrm{a}$ \\
BSA-078 & $3.7 \pm 0.1 \mathrm{a}$ & $6.2 \pm 0.2 \mathrm{~d}$ & $1.5 \pm 0.3 \mathrm{a}$ \\
BSA-101 & $3.6 \pm 0.1 \mathrm{a}$ & $5.9 \pm 0.1 \mathrm{~d}$ & $1.8 \pm 0.2 \mathrm{a}$ \\
BSA-119 & $3.6 \pm 0.0 \mathrm{a}$ & $8.8 \pm 0.1 \mathrm{a}$ & $1.5 \pm 0.3 \mathrm{a}$ \\
BSA-144 & $3.6 \pm 0.0 \mathrm{a}$ & $7.1 \pm 0.3 \mathrm{c}$ & $1.6 \pm 0.3 \mathrm{a}$ \\
BSB-032 & $3.6 \pm 0.1 \mathrm{a}$ & $6.1 \pm 0.2 \mathrm{~d}$ & $1.7 \pm 0.2 \mathrm{a}$ \\
BSB-127 & $3.5 \pm 0.1 \mathrm{a}$ & $6.2 \pm 0.2 \mathrm{~d}$ & $1.8 \pm 0.2 \mathrm{a}$ \\
\hline
\end{tabular}

\footnotetext{
${ }^{\mathrm{z})}$ Mean separation within columns by Duncan's multiple range tests $(P \leq 0.05, \mathrm{n}=3)$.
} 
genotype had the lowest SSC, although it was not significantly different than the SSC of the original genotype.

\section{Mineral content}

The mineral contents of the hybrid boysenberry genotypes are provided in Table 3. Potassium, calcium, and magnesium were the most abundant minerals in the fruits. Among the minerals, potassium was detected at the highest concentrations for all genotypes, with BSB127 having the highest potassium content. The mutant genotypes contained less calcium and magnesium than the boysenberry and blackberry cultivars. The boysenberry cultivar (BS_PI) had the highest fruit sodium content. Meanwhile, there were no significant differences in the iron and zinc contents among the genotypes.

\section{Fatty acid composition}

The fruit fatty acid compositions of the hybrid boysenberry genotypes are presented in Table 4 and Supplementary Fig. S1. The GC-MS chromatograms revealed the presence of five fatty acids (i.e., palmitic acid, stearic acid, oleic acid, linoleic acid, and linolenic acid). Linoleic acid was the major fatty acid present in fruits, ranging from $65.00 \%$ (BSA036) to $67.61 \%$ (BS PI). The saturated fatty acid (SFA) content ranged from 7.92\% (BSA119) to $9.33 \%$ (BSA036), while the unsaturated fatty

Table 3. Mineral content of fruit in hybrid boysenberry genotypes.

$(\mathrm{mg} / 100 \mathrm{~g})$

\begin{tabular}{lcccccc}
\hline \multicolumn{1}{c}{ Line } & $\mathrm{Ca}$ & $\mathrm{Mg}$ & $\mathrm{K}$ & $\mathrm{Na}$ & $\mathrm{Fe}$ & $\mathrm{Zn}$ \\
\hline BS_PI & $22.88 \mathrm{a}^{\mathrm{a})}$ & $18.14 \mathrm{a}^{\mathrm{z})}$ & $181.70 \mathrm{~b}^{\mathrm{z})}$ & $3.03 \mathrm{a}^{\mathrm{z}}$ & $0.57 \mathrm{a}^{\mathrm{z})}$ & $0.39 \mathrm{a}^{\mathrm{z})}$ \\
Blackberry (V3) & $23.03 \mathrm{a}$ & $16.97 \mathrm{a}$ & $123.60 \mathrm{~g}$ & $1.45 \mathrm{~b}$ & $0.34 \mathrm{a}$ & $0.17 \mathrm{a}$ \\
BS_Hybrid & $19.47 \mathrm{~b}$ & $8.91 \mathrm{c}$ & $111.80 \mathrm{~h}$ & $0.99 \mathrm{~b}$ & $0.27 \mathrm{a}$ & $0.21 \mathrm{a}$ \\
BSA-036 & $17.45 \mathrm{~b}$ & $14.20 \mathrm{~b}$ & $144.80 \mathrm{e}$ & $0.65 \mathrm{~b}$ & $0.37 \mathrm{a}$ & $0.31 \mathrm{a}$ \\
BSA-065 & $19.68 \mathrm{~b}$ & $15.30 \mathrm{~b}$ & $145.62 \mathrm{e}$ & $1.24 \mathrm{~b}$ & $0.29 \mathrm{a}$ & $0.33 \mathrm{a}$ \\
BSA-078 & $18.69 \mathrm{~b}$ & $13.98 \mathrm{~b}$ & $145.96 \mathrm{e}$ & $0.94 \mathrm{~b}$ & $0.33 \mathrm{a}$ & $0.31 \mathrm{a}$ \\
BSA-101 & $18.66 \mathrm{~b}$ & $14.52 \mathrm{~b}$ & $136.94 \mathrm{f}$ & $0.97 \mathrm{~b}$ & $0.60 \mathrm{a}$ & $0.31 \mathrm{a}$ \\
BSA-119 & $19.42 \mathrm{~b}$ & $15.25 \mathrm{~b}$ & $148.55 \mathrm{e}$ & $1.10 \mathrm{~b}$ & $0.25 \mathrm{a}$ & $0.19 \mathrm{a}$ \\
BSA-144 & $19.74 \mathrm{~b}$ & $14.72 \mathrm{~b}$ & $164.58 \mathrm{~d}$ & $1.26 \mathrm{~b}$ & $0.29 \mathrm{a}$ & $0.20 \mathrm{a}$ \\
BSB-032 & $18.47 \mathrm{~b}$ & $13.97 \mathrm{~b}$ & $174.82 \mathrm{c}$ & $1.53 \mathrm{~b}$ & $0.29 \mathrm{a}$ & $0.18 \mathrm{a}$ \\
BSB-127 & $19.60 \mathrm{~b}$ & $13.97 \mathrm{~b}$ & $193.40 \mathrm{a}$ & $1.63 \mathrm{~b}$ & $0.32 \mathrm{a}$ & $0.28 \mathrm{a}$ \\
\hline
\end{tabular}

${ }^{\mathrm{z})}$ Mean separation within columns by Duncan's multiple range tests $(P \leq 0.05, \mathrm{n}=3)$.

Table 4. Fatty acid composition of fruit in hybrid boysenberry genotypes.

$(\%)$

\begin{tabular}{llllllll}
\hline \hline \multicolumn{1}{c}{ Line } & C16:0 & C18:0 & C18:1 & C18:2 & C18:3 & SFA & UFA \\
\hline BS_PI & $6.70 \mathrm{a}^{\mathrm{z})}$ & $2.32 \mathrm{c}^{\mathrm{z}}$ & $10.55 \mathrm{a}^{\mathrm{z}}$ & $67.61 \mathrm{a}^{\mathrm{z})}$ & $12.83 \mathrm{~b}^{\mathrm{z}}$ & $9.02 \mathrm{a}^{\mathrm{z})}$ & $90.98 \mathrm{a}^{\mathrm{z}}$ \\
Blackberry (V3) & $6.74 \mathrm{a}$ & $1.48 \mathrm{f}$ & $10.66 \mathrm{a}$ & $67.19 \mathrm{a}$ & $13.94 \mathrm{a}$ & $8.22 \mathrm{a}$ & $91.79 \mathrm{a}$ \\
BS_Hybrid & $6.75 \mathrm{a}$ & $2.06 \mathrm{~d}$ & $10.42 \mathrm{a}$ & $66.51 \mathrm{a}$ & $14.27 \mathrm{a}$ & $8.81 \mathrm{a}$ & $91.20 \mathrm{a}$ \\
BSA-036 & $6.32 \mathrm{a}$ & $3.01 \mathrm{a}$ & $10.93 \mathrm{a}$ & $65.00 \mathrm{~b}$ & $14.76 \mathrm{a}$ & $9.33 \mathrm{a}$ & $90.68 \mathrm{a}$ \\
BSA-065 & $6.39 \mathrm{a}$ & $2.52 \mathrm{a}$ & $10.79 \mathrm{a}$ & $66.87 \mathrm{a}$ & $13.44 \mathrm{a}$ & $8.91 \mathrm{a}$ & $91.10 \mathrm{a}$ \\
BSA-078 & $6.28 \mathrm{a}$ & $2.85 \mathrm{a}$ & $10.43 \mathrm{a}$ & $66.57 \mathrm{a}$ & $13.89 \mathrm{a}$ & $9.12 \mathrm{a}$ & $90.88 \mathrm{a}$ \\
BSA-101 & $6.56 \mathrm{a}$ & $1.92 \mathrm{e}$ & $11.02 \mathrm{a}$ & $66.98 \mathrm{a}$ & $13.54 \mathrm{a}$ & $8.47 \mathrm{a}$ & $91.53 \mathrm{a}$ \\
BSA-119 & $6.06 \mathrm{a}$ & $1.86 \mathrm{e}$ & $10.12 \mathrm{a}$ & $67.52 \mathrm{a}$ & $14.45 \mathrm{a}$ & $7.92 \mathrm{a}$ & $92.08 \mathrm{a}$ \\
BSA-144 & $6.56 \mathrm{a}$ & $2.44 \mathrm{~b}$ & $10.99 \mathrm{a}$ & $65.99 \mathrm{a}$ & $14.03 \mathrm{a}$ & $9.00 \mathrm{a}$ & $91.01 \mathrm{a}$ \\
BSB-032 & $6.47 \mathrm{a}$ & $2.60 \mathrm{a}$ & $10.97 \mathrm{a}$ & $66.49 \mathrm{a}$ & $13.48 \mathrm{a}$ & $9.07 \mathrm{a}$ & $90.94 \mathrm{a}$ \\
BSB-127 & $6.67 \mathrm{a}$ & $2.23 \mathrm{c}$ & $10.44 \mathrm{a}$ & $66.68 \mathrm{a}$ & $13.99 \mathrm{a}$ & $8.90 \mathrm{a}$ & $91.11 \mathrm{a}$ \\
\hline
\end{tabular}

$\mathrm{C} 16: 0=$ palmitic acid, $\mathrm{C} 18: 0=$ stearic acid, C18:1 = oleic acid, C18:2 = linoleic acid, C18:3 = $\alpha$-linolenic acid. ${ }^{\mathrm{z})}$ Mean separation within columns by Duncan's multiple range tests $(P \leq 0.05, \mathrm{n}=3)$.

SFA: saturated fatty acid, UFA: unsaturated fatty acid. 
acid (UFA) content ranged from $90.68 \%$ (BSA036) to $92.08 \%$ (BSA119). There were no significant differences in the contents of palmitic acid, oleic acid, SFA, and UFA among all genotypes.

\section{Ellagic acid content}

The ellagic acid contents are presented in Fig. 2. We observed significant differences among the analyzed hybrid boysenberry genotypes. The BSB127 genotype had the highest ellagic acid concentration $(46.40 \pm 1.33 \mathrm{mg} / 100 \mathrm{~g})$, followed by blackberry $(39.31 \pm 0.05 \mathrm{mg} / 100 \mathrm{~g})$, BSA036 $(36.05 \pm 0.61 \mathrm{mg} / 100 \mathrm{~g})$, BSA101 $(20.04 \pm 0.43 \mathrm{mg} / 100 \mathrm{~g})$, boysenberry and BSA144 (13.37 $\pm 0.19 \mathrm{mg} / 100 \mathrm{~g})$,
BSA032 $(11.89 \pm 1.33 \mathrm{mg} / 100 \mathrm{~g}), \mathrm{BSA} 078(12.30 \pm 0.18$ $\mathrm{mg} / 100 \mathrm{~g})$, BSA119 $(11.13 \pm 0.33 \mathrm{mg} / 100 \mathrm{~g})$, and BSA065 $(8.72 \pm 0.36 \mathrm{mg} / 100 \mathrm{~g})$.

\section{Anthocyanin content}

The anthocyanin contents of the hybrid boysenberry genotypes are provided in Table 5 and Supplementrary Fig. S2. Cyanidin- 3-O-glucoside $\left(\mathrm{M}-\mathrm{H}^{+}, 449 \mathrm{~m} / \mathrm{z}\right)$ was the major blackberry anthocyanin. In contrast, cyanidin-3-Osophoroside $\left(\mathrm{M}-\mathrm{H}^{+}, 611 \mathrm{~m} / \mathrm{z}\right)$ and cyanidin-3-O-glucoside were the major anthocyanins in boysenberry and BS Hybrid lines.

The BSA078 genotype had the highest cyanidin-3-O-

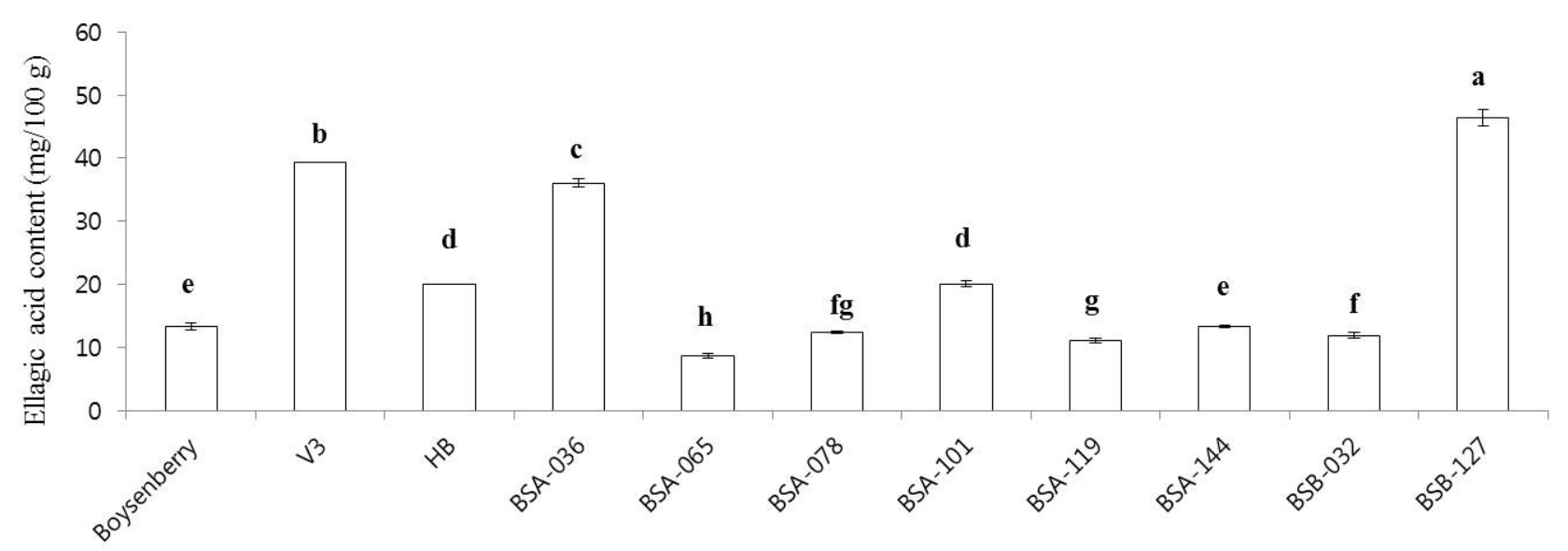

Fig. 2. Ellagic acid content in hybrid boysenberry genotypes. The letters above each point indicate a significant difference at the 5\% level (Duncan's multiple range tests, $n=3$ ).

Table 5. Anthocyanin content of fruit for hybrid boysenberry genotypes.

$(\mathrm{mg} / 100 \mathrm{~g})$

\begin{tabular}{lccc}
\hline \hline Line & Cy-3-O-Sop & Cy-3-O-Glu & Total anthocyanin \\
\hline Boysenberry & $48.3 \pm 08.9 \mathrm{de}^{\mathrm{z})}$ & $177.4 \pm 8.7 \mathrm{~g}^{\mathrm{z})}$ & $225.7 \pm 0.2 \mathrm{~g}^{\mathrm{z})}$ \\
Blackberry & NDf & $184.0 \pm 2.0 \mathrm{~g}$ & $184.0 \pm 2.0 \mathrm{~h}$ \\
BS_Hybrid & $72.6 \pm 12.4 \mathrm{bc}$ & $309.4 \pm 6.6 \mathrm{~d}$ & $382.0 \pm 5.8 \mathrm{~d}$ \\
BSA-036 & $82.3 \pm 14.0 \mathrm{~b}$ & $344.6 \pm 7.8 \mathrm{bc}$ & $426.9 \pm 6.3 \mathrm{c}$ \\
BSA-065 & $56.5 \pm 09.5 \mathrm{c}$ & $205.4 \pm 8.9 \mathrm{f}$ & $261.9 \pm 0.7 \mathrm{f}$ \\
BSA-078 & $107.5 \pm 19.2 \mathrm{a}$ & $360.5 \pm 16.2 \mathrm{ab}$ & $467.9 \pm 3.0 \mathrm{a}$ \\
BSA-101 & $91.2 \pm 15.8 \mathrm{ab}$ & $373.7 \pm 09.1 \mathrm{a}$ & $464.9 \pm 6.7 \mathrm{a}$ \\
BSA-119 & $71.2 \pm 12.3 \mathrm{bc}$ & $273.3 \pm 08.6 \mathrm{e}$ & $344.4 \pm 3.7 \mathrm{e}$ \\
BSA-144 & $33.6 \pm 05.7 \mathrm{e}$ & $118.3 \pm 03.4 \mathrm{~h}$ & $152.0 \pm 2.3 \mathrm{i}$ \\
BSB-032 & $40.4 \pm 06.9 \mathrm{de}$ & $95.2 \pm 03.5 \mathrm{i}$ & $135.5 \pm 3.4 \mathrm{j}$ \\
BSB-127 & $85.9 \pm 14.4 \mathrm{~b}$ & $353.4 \pm 08.2 \mathrm{~b}$ & $439.3 \pm 6.2 \mathrm{~b}$ \\
\hline
\end{tabular}

${ }^{\mathrm{z})}$ Mean separation within columns by Duncan's multiple range tests $(P \leq 0.05, \mathrm{n}=3)$.

Cy-3-O-Sop: Cyanidin-3-O-sophoroside $\left(\mathrm{M}-\mathrm{H}^{+}, 611 \mathrm{~m} / \mathrm{z}\right), \mathrm{Cy}-3-O-G l u:$ Cyanidin-3-O-glucoside $\left(\mathrm{M}-\mathrm{H}^{+}, 449 \mathrm{~m} / \mathrm{z}\right), \mathrm{ND}$ : Not detected. 
sophoroside concentration (107.5 mg/100 g), followed by BSA101 (91.2 mg/100 g), BSB127 (85.9 mg/100 g), BSA036 $(82.3 \mathrm{mg} / 100 \mathrm{~g})$, BS_Hybrid $(72.6 \mathrm{mg} / 100 \mathrm{~g})$, BSA119 $(71.2 \mathrm{mg} / 100 \mathrm{~g})$, BSA065 $(56.5 \mathrm{mg} / 100 \mathrm{~g})$, boysenberry (48.3 mg/100 g), BSB032 (40.4 mg/100 g), and BSA114 (33.6 mg/100 g). Cyanidin-3-O-sophoroside pigments were undetectable in blackberry fruits. The highest cyanidin-3-O-glucoside concentration (373.7 $\mathrm{mg} / 100 \mathrm{~g}$ ) was observed for the BSA101 cultivar, followed by BSA078 (360.5 mg/100 g), BSB127 (353.4 mg/100 g), BSA36 (344.6 mg/100 g), BS_Hybrid (309.4 mg/100 g), BSA119 (273.3 mg/100 g), BSA065 (205.4 mg/100 g), blackberry $(184.0 \mathrm{mg} / 100 \mathrm{~g})$, boysenberry $(177.4 \mathrm{mg} / 100$ g), BSA144 (118.3 mg/100 g), and BSB032 (95.2 mg/100 g). The total anthocyanin contents differed significantly among the genotypes, ranging from $135.5 \mathrm{mg} / 100 \mathrm{~g}$ (BSB032) to $467.9 \mathrm{mg} / 100 \mathrm{~g}$ (BSA078) (i.e., a 3.5-fold difference among genotypes).

\section{DISCUSSION}

A limited number of Rubus genetic resources have been established based on fruit quality and functional compound contents. This has limited the application of cross-breeding to generate novel Rubus varieties. However, induced mutations change only one or a few specific traits of an elite cultivar, and may be useful for improving fruit production (Predieri 2001; Basaran and Kepenek 2011). In this study, the BS_Hybrid genotype, which was obtained from crosses between thornless blackberry (R. fruticosus L. cv. V3) and boysenberry, has unfavorable fruit characteristics such as a malformed fruit and relatively low sugar content. In contrast, the eight mutant genotypes produced by the gamma irradiation of BS_Hybrid explants, exhibited improved agronomic characteristics, such as higher fruit yields and sugar contents than the original parent.

The $\mathrm{pH}, \mathrm{SSC}$, and titratable acidity are very important determinants of fruit quality. Previous studies concluded that variations in these traits depend on the genotype, harvest time, and environmental conditions (Connor et al. 2005; Basaran and Kepenek 2011; Ryu et al. 2016). The SSC was higher for BSA119 and BSA144 than for the original genotype. These genotypes may be useful as potential sources of fresh fruit materials. The analyzed Rubus fruits contained high levels of potassium, calcium and magnesium, which is consistent with the findings of Ryu et al. (2016). Fruit mineral contents are considerably influenced by soil conditions, fertilizer treatments, climatic conditions, and cultivars (Guedes et al. 2013). Because all of the genotypes were grown under the same conditions, any differences in mineral content were likely cultivardependent, which may have implications for the selection of Rubus breeding lines (Clark et al. 2007). All of the mutant genotypes contained less calcium and magnesium than the boysenberry and blackberry cultivars. In contrast, the BSB127 potassium content was approximately 1.7 -fold higher than that of the original genotypes.

Edible oils have been extracted and used as sources of food ingredients since ancient times (Parry et al. 2005; Van Hoed et al. 2009; Ferreira de Araujo et al. 2011). Linoleic acid was the most abundant fatty acid in all examined hybrid boysenberry genotypes. Additionally, the fruits contained very high levels of linoleic acids (65.00-67.61\%) and UFA (90.68-92.08\%). The observed linoleic acid levels in hybrid boysenberry genotypes were higher than those reported for different berries (i.e., red raspberry, marionberry, boysenberry, and blueberry) (Parry et al. 2005; Kaume et al. 2012). The UFA concentrations for all hybrid boysenberry genotypes were similar to those reported by Parry et al. (2005) (e.g., 91.3\% for a boysenberry cultivar). Previous studies confirmed that Rubus fruit fatty acid compositions are strongly influenced by genotype, maturation stage, and climate (Parry et al. 2005; Van Hoed et al. 2009). However, in the present study, there were no significant differences in the SFA and UFA contents of all genotypes.

We observed significant differences in the fruit ellagic acid contents among hybrid boysenberry genotypes. The ellagic acid levels of the BS_PI, BS_Hybrid, BSA065, BSA078, BSA101, BSA119, BSA144, and BSA032 genotypes were lower than those of previously analyzed blackberry mutant lines (Ryu et al. 2016). Ellagic acid contents generally decrease as fruits mature (Ryu et al. 2016). The ellagic acid levels of the blackberry (V3), BSA036, and BSB127 genotypes were similar to those 
reported by Ryu et al. (2016) (i.e., 35-47 mg/100 g for ripe blackberry fruits). In the current study, the highest ellagic acid concentration was observed for the BSB127 fruits.

Anthocyanins are important for responses to oxidative stress because of their ability to quickly scavenge reactive oxygen species (Lee et al. 2014; Ryu et al. 2016). The major anthocyanin in blackberries is cyanidin-3-O-glucoside, which can prevent cell damage, and may be beneficial in treatments for obesity and various cancers (Ghosh et al. 2006; Cho et al. 2015). The predominant anthocyanins in boysenberries are the disaccharides cyanidin-3-O-sophoroside and cyanidin-3-O-glucoside (Cooney et al. 2004; Fan-Chiang and Wrolatad 2005; Ghosh et al. 2006). Cyanidin-3-O-sophoroside is a natural colorant in cherries, raspberries, and boysenberries (Sugimoto et al. 2003; Cooney et al. 2004). This compound is important because it protects against oxidative stress and DNA damage, and may have beneficial health effects for diabetics (Sugimoto et al. 2003; Cooney et al. 2004; Ghosh et al. 2006). The anthocyanin concentrations of the hybrid boysenberry genotypes included in the current study ranged from 135.5 $\mathrm{mg} / 100 \mathrm{~g}$ to $467.9 \mathrm{mg} / 100 \mathrm{~g}$. These findings are similar to those described by Ryu et al. (2016) (i.e., 191.6-558.2 $\mathrm{mg} / 100 \mathrm{~g}$ for five mutant blackberry cultivars). The highest anthocyanin content was detected in the BSB127 genotype. Lee et al. (2012) reported that anthocyanins (e.g., cyanidin-3- $O$-sophoroside, cyanidin-3-O-glucosylrutinoside, and cyanidin-3-O-glucoside), ellagic acid, and folate exhibit antioxidant activities. Ryu et al. (2016) concluded that the antioxidant activities of blackberries are correlated with total anthocyanin contents $(P \leq 0.05)$. The application of Rubus species as a resource for functional compounds may result in an increase in Rubus fruit consumption (Cho et al. 2015; Ryu et al. 2016). Additionally, breeding novel Rubus cultivars with high anthocyanin and ellagic acid concentrations may be possible. Our results suggest that the BSA078, BSA101, and BSB127 genotypes are potentially the most appropriate materials for improving the health benefits of fruits.

In this study, we obtained abundant information about the nutritional characteristics and functional compounds of eleven hybrid boysenberry. Among the detected mineral, potassium was found to be the most abundant in all the genotypes. As for the detected fatty acid, linoleic acid (C18:2) was found as a major one. The major anthocyanin in boysenberry, BS_bybrid and mutant lines were cyanidin-3-O-glucoside and cyanidin-3-O-sophoroside. Whereas, cyanidin-3-O-sophoroside compound was not detected in blackberry. Among the experimental genotypes even BSA119 seemed to have a high in soluble solids content. In addition, our results suggest that the BSA078, BSA101, and BSB127 genotypes are the most appropriate for the selection of functional boysenberry because they contained higher antioxidant components (anthocyanin and ellagic acid) contents.

\section{ACKNOWLEDGEMENTS}

This study was supported by Korea Institute of Planning and Evaluation for Technology in Food, Agriculture, Forestry and Fisheries (IPET) through Agri-Bio industry Technology Development Program, funded by Ministry of Agriculture, Food and Rural Affairs (MAFRA), Republic of Korea (Grant number: 315025031SB010)

\section{REFERENCES}

AOAC. 1995. Official Methods of Analyses. 16th ed. Association of Official Analytical Chemists.Washington, DC, USA.

Basaran P, Kepenek K. 2011. Fruit quality attributes of blackberry (Rubus sanctus) mutants obtained by ${ }^{60} \mathrm{Co}$ gamma irradiation. Biotechnol. Bioprocess Eng. 16: 587-592.

Cho BO, Ryu HW, Lee CW, Jin CH, Seo WD, Ryu J, et al. 2015. Protective effects of new blackberry cultivar MNU-32 extracts against $\mathrm{H}_{2} \mathrm{O}_{2}$-induced oxidative stress in HepG2 cells. Food Sci. Biotechnol. 24: 643-650.

Clark JR. Stafne ET, Hall HK, Finn CE. 2007. Blackberry breeding and Genetics, p.19-53. In: J. Janick (ed.). Plant breeding reviews. John Wiley and Sons Inc., New York, NY. USA.

Cooney JM, Dwayne J, Jensen DJ, Tony K, McGhie TK. 2004. LC-MS identification of anthocyanins in boysenberry extract and anthocyanin metabolites in human urine 
following dosing. J. Sci. Food. Agric. 84: 237-245.

Connor AM, Finn CE, McGhie TK, Alspach PA. 2005.

Genetic and environmental variation in anthocyanins and their relationship to antioxidant activity in blackberry and hybrid berry cultivars. J. Amer. Soc. Hort. Sci. 130: 680-687.

Donini B. 1982. Mutagenesis applied to improve fruit trees: techniques, methods and evaluation or radiation induced mutations, p.29-36. In: IAEA (ed.). Induced mutations in vegetatively propageted plants II. IAEA, Vienna, Austria.

Fan-Chiang HJ, Wrolstad RE. 2005. Anthocyanin pigment composition of blackberries. J. Food Sci. 70: C198-C202.

Ferreira de Araujo PR, da Silva SV, Rodrigues MA, Gevehr FC, Silva JA, da Silva RR. 2011. Benefits of blackberry nectar (Rubus spp.) relative to hypercholesterolemia and lipid peroxidation. Nutr. Hosp. 26: 984-990.

Ghosh D, McGhie TK, Zhang J, Adaim A, Skinner M. 2006. Effects of anthocyanins and other phenolics of boysenberry and blackcurrant as inhibitors of oxidative stress and damage to cellular DNA in SH-SY5Y and HL-60 cells. J. Sci. Food. Agric. 86: 678-686.

Guedes MNS, Abreu CMP, Maro LAC, Pio R, Abreu JR, Oliverira JO. 2013. Chemical characterization and mineral levels in the fruits of blackberry cultivars grown in a tropical climate at an elevation. Acta Sci. Agron. 35: 191-196.

Jo YD, Kim SH, Hwang JE, Kim YS, Kang HS, Kim SW, et al. 2016. Construction of mutation populations by gamma-ray and carbon beam irradiation in chili pepper (Capsicum annuum L.). Hortic. Environ. Biotechnol. 57: 606-614.

Kaume L, Howard LR, Devareddy L. 2012. The blackberry fruit: a review on its composition and chemistry, metabolism and bioavailability, and health benefits. J. Agr. Food Chem. 60: 5716-5727.

Kim SH, Kim DS, Kim JB, Ha BK, Lee DM, Song HS, et al. 2015. Hibiscus syriacus 'Dasom', A New Flower-Color Mutant Variety Developed by Radiation Breeding. Kor. J. Hort. Sci. Technol. 33: 298-301.
Lee HH, Moon YS, Yun HK, Park PJ, Kwak EJ. 2014. Contents of bioactive constituents and antioxidant activities of cultivated and wild raspberries. Kor. J. Hort. Sci. Technol. 32: 115-122.

Lee J. Dossett M, Finn CE. 2012. Rubus fruit phenolic research: The good, the bad, and the confusing. Food Chem. 130: 785-796.

Parry J, Su L, Luther M, Zhou K, Yurawecz P, Whittaker P, et al. 2005. Fatty acid composition and antioxidant properties of cold-pressed marionberry, boysenberry, red raspberry, and blueberry seed oils. J. Agric. Food Chem. 53: $566-573$.

Predieri S. 2001. Mutation induction and tissue culture in improving fruits. Plant Cell Tissue Organ Cult. 64: 185-210.

Ryu J, Kwon SJ, Jo YD, Jin CH, Nam BM, Lee SY, et al. 2016. Comparison of phytochemicals and antioxidant activity in blackberry (Rubus fruticosus L.) fruits of mutant lines at the different harvest time. Plant Breed.Biotech. 4: 242-251.

Shin JS, Lee JC, Sim OK, Yoon TY, Cho HJ, Kim EY. 2008. Plant regeneration via multiple shoot formation from sucker explant of hybrid blackberry (Rubus fruticosus L. $\times R$. parvifolius L.). Korean J. Plant Res. 21: 111-116.

Sugimoto E, Igarashi K, Kubo K, Molyneux J, Kubomura K. 2003. Protective effects of boysenberry anthocyanins on oxidative stress in diabetic rats. Food Sci. Technol. Res. 9: 345-349.

Van Hoed V, Declercq ND, Echim C, Andjelkovic M, Leber E, Dewettinck K, et al. 2009. Berry seeds: A source of specialty oils with high content of bioactives and nutritional value. Food Lipids 16: 33-49.

Wada L, Ou B. 2002. Antioxidant activity and phenolic content of oregon caneberries. J. Agric. Food Chem. 50: 3495-3500.

Zafra-Stone S, Yasmin T, Bagchi M, Chatterjee A, Vinson JA, Bagchi D. 2007. Berry anthocyanins as novel antioxidants in human health and disease prevention. Mol. Nutr. Food Res. 51: 675-683. 